\title{
Role of anti-GQIB antibody in differential diagnosis of acute ophthalmoparesis
}

CASE REPORT

This article was published in the following Dove Press journal:

Neuropsychiatric Disease and Treatment

2 April 2010

Number of times this article has been viewed

\author{
E Ece Boylu \\ R Erdem Toğrol \\ Mehmet Güney Șenol \\ M Fatih Özdağ \\ Mehmet Saraçoğlu \\ GATA Hadarpașa Educational \\ and Research Hospital, Department \\ of Neurology, İstanbul, Turkey
}

Correspondence: E Ece Boylu GATA Haydarpașa Eğitim Hastanesi, Nöroloji Servisi, Tıbbiye Caddesi No 2 Kadıköy, İstanbul, Turkey Email eceboylu@yahoo.com

\begin{abstract}
Miller Fisher syndrome (MFS) is a triad of total external ophthalmoplegia, ataxia, and areflexia, while botulism has the usual clinical presentation of involvement of cranial muscles and palsies with blurred vision, diplopia, ptosis, dilated pupils, and facial paralysis, caused by a bacterial neurotoxin which attacks proteins involved in presynaptic vesicle release. In this report, we needed to make the differential diagnosis between MFS and botulism in a patient who presented with acute ophthalmoparesis and a history of diarrhea three days before, which started two days after consuming tinned food. Routine laboratory, neurophysiologic, and imaging investigations were normal. A clinical diagnosis of Miller Fisher syndrome was reached by anti-ganglioside GQ1B and GM1 Ig G and M antibody investigations which proved positive. The patient was treated with intravenous immunoglobulin two weeks after (in the late period) the symptoms started and he has recovered completely. Systemic autoimmune diseases should be considered in patients with bilateral ophthalmoparesis. As in the present patient, the evaluation of specific antibodies helps in the diagnosis and thus early effective treatment is possible.
\end{abstract}

Keywords: anti-ganglioside antibody, botulism, Miller Fisher syndrome, ophthalmoparesis

\section{Introduction}

Miller Fisher syndrome (MFS), first described in 1956, is a triad of total external ophthalmoplegia, ataxia, and absent deep tendon reflexes (areflexia). It usually has a monophasic course and is a less commonly seen subtype of Guillain Barré syndrome (GBS). ${ }^{1}$ Botulism is caused by a bacterial neurotoxin, typically botulinum toxin type A, B, or E produced by Clostridium botulinum. This toxin attacks proteins involved in presynaptic vesicle release. The usual clinical presentation is cranial muscle involvement, ie, extraocular muscle palsies with blurred vision, diplopia, ptosis, dilated pupils, and facial paralysis. Speaking and swallowing problems may occur. Eventually flaccid limb paralysis and respiratory dysfunction may develop and the disease may be lethal. ${ }^{2}$

In 1992, acute phase immunoglobulin G (IgG) antibodies to GQ1b ganglioside were reported as a highly specific serum marker for MFS. ${ }^{3,4}$ Over $90 \%$ of MFS cases have acute phase anti-GQ1b ganglioside antibodies which are particularly associated with ophthalmologic disease. ${ }^{5}$ Miller Fisher syndrome, Birkerstaff brainstem encephalitis, and Guillain Barre syndrome have been collectively called "anti-GQ1b IgG antibody syndrome". ${ }^{6}$ The symptoms seen in MFS are related to cranial nerves III, IV, and VI, and it has been suggested by some biochemical studies, and supported by immunohistochemical studies, that these cranial nerves contain a considerable amount of GQ1b. The serum of affected individuals contains a blocking factor in the 
IgG fraction which acts in a manner similar to some biologic toxins. The distal nerve terminal lacks the blood-nerve barrier, and is accessible for circulating antibodies. Thus, the cranial nerve findings may be the result of the direct action of the antibodies on the neuromuscular junction between the cranial nerves and ocular muscles. ${ }^{1,7}$

There are a number of cases in the literature in which the differential diagnosis between botulism and GBS or MFS has had to be made very cautiously. ${ }^{2,8-10}$ In this report, the importance of anti-GQ1b antibody titers in the differential diagnosis of MFS and botulism was discussed.

\section{Case report}

A 16-year-old male presented with a three-day history of diarrhea, starting two days after eating tinned beans, followed by a hamburger and a toasted sandwich a few hours later. Two days after the onset of the diarrhea, he developed fatigue, nausea, and vomiting. Acute gastroenteritis therapy was started. One day after this, he developed double and blurred vision, dizziness, and loss of balance. On admission, his eye movements were restricted on both sides, worse on the left, pupils were midriatic and unreactive to light, and he had bilateral semi-ptosis. Limb power was normal, tendon reflexes were decreased, and plantar responses were bilaterally flexor. Cerebellar tests, sensory examination, and examination of other systems were normal. Routine blood tests including syphilis serology, radiological examination including cranial computed tomography (CT) and magnetic resonance imaging (MRI) scans, and electrocardiogram were normal. Cerebrospinal fluid (CSF) studies including cytology were normal; the CSF was clear, with normal opening pressure. Electroneurophysiological examination, sensory and motor nerve conduction studies, $\mathrm{F}$ waves, and $\mathrm{H}$ reflexes were normal (Tables 1 and 2). On repetitive stimulation, no decremental or incremental response was observed. The most likely differential diagnosis was between botulism and MFS. Stool and serum samples were sent for botulism toxin assay, along with antiganglioside GQ1B and GM1 Ig G and M antibodies.

After consulting with the infectious diseases department, crystallized penicillin treatment plus trivalent botulinum anti-toxin against toxins A, B, and E were given. During his follow-up in the neurologic intensive care unit, little change in his symptoms occurred other than the ophthalmoparesis becoming symmetrical.

Two weeks later, an elevated titer of $\operatorname{IgG}$ and IgM anti-GQ1B was reported. Intravenous immunoglobulin (IVIG) therapy $(0.4 \mathrm{~g} / \mathrm{kg} /$ day for five days $)$ was started for the treatment of MFS. After the treatment, the eye movements improved, ptosis slowly resolved, and diplopia disappeared. The tendon reflexes were present but still hypoactive in the upper limbs. The patient is still under follow-up by our department. Fourteen months after the onset of his symptoms, he has no complaints and his neurologic examination is normal except for hypoactive tendon reflexes.

\section{Discussion}

GBS is usually considered to be the prototype of post-infectious neuroimmune disease. Epidemiologic studies have indicated previous infection with certain bacteria, eg, Campylobacter jejuni and viruses, eg, cytomegalovirus and Epstein-Barr viruses. ${ }^{11,12}$ The syndrome has several pathologic subtypes, the most common being multifocal demyelinating polyneuropathy. Miller Fisher syndrome is a less commonly seen subtype, with a classical triad of total external ophthalmoplegia, ataxia, and areflexia. ${ }^{13}$ Recent research on GBS and the MFS variant has focused on the forms mediated by antiganglioside antibodies in which correlations have been established between antiganglioside antibodies and specific clinical phenotypes, notably between anti-GM1/GD1a antibodies and the acute motor axonal variant, and anti-GQ1b/GT1a antibodies and MFS. ${ }^{14,15}$ In GBS the frequency of these antibodies varies and has been reported to be $29 \%-70 \%$, whereas patients

Table I Motor nerve conduction study of the patient

\begin{tabular}{lllll}
\hline & $\begin{array}{l}\text { Median } \\
\text { Right/Left }\end{array}$ & $\begin{array}{l}\text { Ulnar } \\
\text { Right/Left }\end{array}$ & $\begin{array}{l}\text { Peroneal } \\
\text { Right/Left }\end{array}$ & $\begin{array}{l}\text { Tibial } \\
\text { Right/Left }\end{array}$ \\
\hline Latency (msec) & $3.30 / 3.40$ & $2.65-6.25-7.30 /$ & $3.45-9.10-10.75 /$ & $4.25-12.90 /$ \\
(Proximal-distal) & & $2.30-6.05-7.20$ & $3.55-9.80-10.80$ & $4.70-13.05$ \\
Nerve conduction velocity & $60.3 / 54.8$ & $58.3-66.7 /$ & $52.2-57.5 /$ & $46.2 / 49.1$ \\
$(\mathrm{~m} / \mathrm{sec}$ ) (Proximal-distal) & & $56.3-63.4$ & $48.7-61.5$ & $4.9-5.1 /$ \\
Compound muscle action & $7.3-7.2 /$ & $7.2-6.6-7.1 /$ & $4.5-4.3-4.4 /$ & $4.6-4.4$ \\
potential (CMAP/mV) & $6.3-6.2$ & $6.3-5.9-6.0$ & $4.3 / 4.6 / 4.2$ & \\
(Proximal-distal) & & & & $49.3 / 50.7$ \\
FWave latency $(\mathrm{ms})$ & $24.3 / 23.5$ & $26.7 / 25.9$ & $45.7 / 47.2$ & \\
\hline
\end{tabular}


Table 2 Sensory nerve conduction study of the patient

\begin{tabular}{llll}
\hline & Median & Ulnar & Sural \\
\hline Latency (msec) & $2.40 / 2.30$ & $2.05 / 2.15$ & $2.60 / 2.70$ \\
$\begin{array}{l}\text { Sensory nerve action } \\
\text { potentials (SNAP/ } \mu \mathrm{V})\end{array}$ & $42.3 / 48.7$ & $33.7 / 28.5$ & $17.5 / 18.3$ \\
$\begin{array}{l}\text { Nerve conduction } \\
\text { velocity }(\mathrm{m} / \mathrm{sec})\end{array}$ & $58.3 / 60.8$ & $58.5 / 55.8$ & $53.8 / 51.8$ \\
\hline
\end{tabular}

with MFS have a much higher frequency of the antibodies, probably around $95 \% .^{16,17}$

Botulism is a potentially life-threatening condition caused by botulinum neurotoxin that acts against proteins involved in presynaptic vesicle release. The neurotoxin is formed during the growth of the spore-forming bacterium $C$. botulinum. It can enter the body via the gastrointestinal tract or through mucous membranes, ie, the eyes or the respiratory tract. The most common form is food-borne botulism and the most frequent source is home-canned foods. This form may be manifested by gastrointestinal symptoms, ie, nausea, vomiting, and constipation, in addition to the general signs of botulism discussed below. ${ }^{8,18}$ After entering the body, the neurotoxin is absorbed into the circulation, and reaches motor nerve endings where it blocks neurotransmitter release. This may occur as rapidly as 12 hours after the entry of the neurotoxin inside the body (usually within the first 36 hours). Typical clinical symptoms include cranial muscle involvement, ie, double vision, dilated pupils, slurred speech, dry mouth, difficulty in swallowing and speaking, and facial paralysis. As the clinical picture progresses, descending flaccid paralysis of the limbs and respiratory dysfunction can occur, and may be lethal. ${ }^{18,19}$ The differential diagnosis includes GBS, MFS, chemical intoxication, stroke, and other food poisonings. Being a potentially lethal condition, the need for a rapid diagnosis and appropriate therapy is obvious. Early diagnosis is important because antitoxin therapy is most likely to be effective when administered early. Recovery time is several weeks to months, depending on the amount of toxin ingested and the toxin type. ${ }^{18}$ The main treatment is intensive symptomatic care with respiratory support. IV administration of trivalent antitoxin towards $\mathrm{A}, \mathrm{B}$, and $\mathrm{E}$ toxins can be used to neutralize the circulating toxin, but the time of administration is important. ${ }^{8,19}$ In our case, although the patient has presented with clinical symptoms suggesting MFS, botulinum toxin intoxication could not be ruled out for the following reasons. Our patient had complained of diarrhea, after eating tinned beans. Later he had developed vomiting, nausea, and acute ophthalmoparesis with unresponsive midriatic pupils (which is rare in MFS but may occur in botulism). This medical history suggested botulism and, because botulism is life-threatening, crystallized penicilin treatment in adition to trivalent botulism antitoxins against $\mathrm{A}, \mathrm{B}$, and $\mathrm{E}$ were administered.

In the case reported by Dörr et al the patient had recurrent MFS with some characteristics of botulism and normal electrophysiologic findings. ${ }^{10}$ The diagnosis was finally made with the help of positive anti-GQ1b antibodies. In the case reported by Chadderdon et al the patient presented with symptoms suggesting either MFS or botulism, and therefore the patient was initially treated for both illnesses. When the results of laboratory tests were available, the botulism toxin assay was positive for type $\mathrm{F}$ toxin, with a culture suggesting Clostridium baratii, while anti-GQ1B antibody tests were negative. Thus, a diagnosis of botulism was made. ${ }^{19}$ In our patient, just after finishing a course of penicillin treatment, the positive anti-GQ1b titer was reported, and thus our final diagnosis was MFS. Since the treatment of the two conditions is completely different, this case report demonstrates the importance of this simple test in the diagnosis and treatment of similarly presenting patients.

MFS cases without ataxia but with positive antibody titers or anti-GQ1b-positive status with ataxia but no opthalmoparesis have also been reported. ${ }^{13,17,20}$ Our patient did not have ataxia or cerebellar findings, but fulfilled the other two criteria for MFS. Unreactive pupils are also an unusual finding in MFS. There are a number of reports of patients with post-infective ophthalmoparesis as well as unreactive midriatic pupils. The patient with recurrent MFS described by Dörr et al had this feature. ${ }^{14}$ Chan et al reported a 35 -year-old female with external ophthalmoplegia, non-reactive pupils, and no dysfunction of the other cranial nerves, muscle tone, tendon reflexes, muscle power, or the cerebellum. This patient also had unresponsive dilated pupils which gradually resolved after IVIG treatment. It is postulated that there is an immunopathologic involvement of the ciliary ganglion and/or denervation supersensitivity of the pupillar sphincter muscles in such patients. ${ }^{21}$ The concept of anti-GQ1b IgG antibody syndrome evolved after the description of atypical cases like the ones discussed above, with features of MFS, ataxic GBS, and other clinical symptoms plus positive anti-ganglioside antibodies. These patients seem to share a common antibody against GQ1b, and their illness has a relatively mild course. ${ }^{21}$ The case described in this report may be accepted as FSH because his illness had a mild and benign course.

The mainstay of therapy is careful intensive care and respiratory support when indicated. More specific treatment is also available. Clinical trials have shown that plasma exchange and IVIG shorten the recovery time if used early. ${ }^{22,23}$ Plasma 
exchange removes the antibodies in the blood mediating the neuropathy, thereby combating the continuous production of new autoantibodies. In a monophasic acute illness like MFS, this seems to be effective, although complete removal of all autoantibodies is impossible. ${ }^{24}$ IVIG is thought to interfere with and prevent the passage of autoimmune T-cells into the blood-nerve barrier and also to downregulate the blockade of antibody production by B-cells, interfere with B-cell proliferaton via blockade of cell surface receptors, and prevent the activation of certain subtypes of B-cell. In addition, IVIG can affect innate immunity by interrupting the steps in the complement activation cascade and blocking Fc-receptor mediated activity, which results in downregulation of macrophage activity. ${ }^{1,22,25}$ In conclusion, IVIG has numerous modes of activation, which culminate in the downregulation of the immune response; many of which may be relevant to neuromuscular disorders and immune neuropathies. ${ }^{25,26}$ In our patient, significant improvement of the symptoms was observed after IVIG therapy.

In conclusion, systemic autoimmune diseases should be considered in patients with bilateral ophthalmoparesis. Occasionally botulism is in the differential diagnosis. As in the present patient, the evaluation of specific antibodies helps in the diagnosis and thus early effective treatment is possible.

\section{Disclosures}

The authors report no conflicts of interest in this work.

\section{References}

1. Winer JB. Guillain Barré syndrome. Mol Pathol. 2001;54:381-385.

2. Dowling PC, Cook SD. Role of infection in Guillain-Barre syndrome: Laboratory confirmation of herpes viruses in 41 cases. Ann Neurol. 1981;9:44-55.

3. Chiba A, Kusunoki S, Shimizu T, et al. Serum IgG antibody to ganglioside GQ1b is a possible marker of Miller Fisher syndrome. Ann Neurol. 1992;31:677-679.

4. Willison HJ, O'Hanlon GM. The immunopathogenesis of Miller Fisher syndrome. J Neuroimmunol. 1999;100(1-2):3-12.

5. O'Hanlon GM, Plomp JJ, Chakrabarti M, et al. Anti-GQ1b ganglioside antibodies mediate complement-dependent destruction of the motor nerve terminal. Brain. 2001;124:893-906.

6. Makino F, Kojima Y, Inoue M, Satoi H, et al. A case of Birkerstaff brainstem encephalitis concomitant with axonal Guillain-Barre syndrome and ballism sucsessfully treated with intravenous immunoglobulin treatment. Rinsho Shinkeigaku. 2008;48:501-504.
7. Winer JB, Hughes RA, Anderson MJ, et al. A prospective study of acute idiopathic neuropathy. II. Antecedent events. J Neurol Neurosurg Psychiatry. 1988;51:613-618.

8. Tornese M, Rossi ML, Coca F, et al. Epidemiology and risk factors associated with foodborne and infant botulism: Where and when. Rev Chilena Infectol. 2008;1:122-134.

9. Susuki K, Takahashi H, Yuki N, et al. Guillian-Barre syndrome mimicking botulism. J Neurol. 2001;248(8):720-721.

10. Dörr J, Dieste FJ, Klaasen van Husen D, et al. A case of recurrent Miller Fisher syndrome mimicking botulism. Neurol Sci. 2006;27:424-425.

11. Chang VH, Robinson LR. Serum positive botulism with neuropathic features. Arch Phys Med Rehabil. 2000;81(1):122-126.

12. Rees JH, Gregson NA, Hughes RA. Anti-ganglioside GM1 antibodies in Guillain-Barre syndrome and their relationship to Campylobacter jejuni infection. Ann Neurol. 1995;38:809-816.

13. Lee SH, Lim GH, Kim JS, et al. Acute ophthalmoplegia (without ataxia) associated with anti-GQ1b antibody. Neurology. 2008;5(71)426-429.

14. Mori M, Kuwabara S, Fukutake T, et al. Clinical features and prognosis of Miller Fisher syndrome. Neurology. 2001;56:1104-1106.

15. Caudie C, Schandelong A, Rapoport F, et al. Anti-GD1b IgG positive case of overlapping Fisher's and Guillain-Barre syndromes. Ann Biol Clin (Paris). 2004;62:591-594.

16. Willison HJ, Plomp JJ. Anti-ganglioside antibodies and the presynaptic motor nerve terminal. Ann N Y Acad Sci. 2008;1132:114-123.

17. Kusunoki S, Chiba A, Kanazawa I. Anti-GQ1b IgG Antibody is associated with ataxia as well as opthalmoplegia. Muscle and Nerve. 1999;22:1071-1074.

18. Dembek ZF, Smith LA, Rusnak JM. Botulism: Cause, effects, diagnosis, clinical and laboratory identification, and treatment modalities. Disaster Med Public Health Prep. 2007;1(2):122-134.

19. Chadderdon SM, Hagg DS, Jacoby DB. Botulism Secondary to Clostridium Baratii Type F Toxin. Chest. 2004;126:947S-948S.

20. Yuki N, Odaka M, Hirata K. Acute Opthalmoparesis (without ataxia) associated with anti-GQ1b IgG antibody. Ophthalmology. 2001;108:196-200.

21. Chan YC, Wilder-Smith E, Chee MWL. Acute opthalmoplegia with pupillary areflexia associated with anti-GQ1b antibody. J Clin Neurosci. 2004; 11:658-660.

22. Plasma Exchange/Sandoglobulin Guillain-Barré Syndrome Trial Group. Randomised trial of plasma exchange, intravenous immunoglobulin, and combined treatments in Guillain-Barré syndrome. Lancet. 1997;349:225-230.

23. van der Meche FG, Schmitz PI. A randomized trial comparing intravenous immunglobulin and plasma exchange in Guillain-Barre syndrome. Dutch Guillain-Barre study group. N Engl J Med. 1992;326: 1123-1129.

24. Lehmann HC, Hartung HP, Hetzel GR, et al. Plasma exchange in neuroimmunological disorders. Part 1: Rationale and treatment of inflammatory central nervous system disorders. Arch Neurol. 2006;63:930-935.

25. Hartung HP. Advances in the understanding of the mechanism of action of IVIG. J Neurol. 2008;255:3-6.

26. Stangel M, Hartung HP, Gold R, Kieseier BC. The significance of intravenous immunoglobulin in treatment of immune-mediated polyneuropathies. Nervenartz. 2009;80:678-687.
Neuropsychiatric Disease and Treatment

\section{Publish your work in this journal}

Neuropsychiatric Disease and Treatment is an international, peerreviewed journal of clinical therapeutics and pharmacology focusing on concise rapid reporting of clinical or pre-clinical studies on a range of neuropsychiatric and neurological disorders. This journal is indexed on PubMed Central, the 'PsycINFO' database and CAS, and is the official

\section{Dovepress}

journal of The International Neuropsychiatric Association (INA). The manuscript management system is completely online and includes a very quick and fair peer-review system, which is all easy to use. Visit $\mathrm{http}: / / \mathrm{www}$.dovepress.com/testimonials.php to read real quotes from published authors. 